International Journal of Current Advanced Research

ISSN: O: 2319-6475, ISSN: P: 2319 - 6505, Impact Factor: SJIF: 5.995

Available Online at www.journalijcar.org

Volume 6; Issue 4; April 2017; Page No. 3306-3308

DOI: http://dx.doi.org/10.24327/ijcar.2017.3308.0257

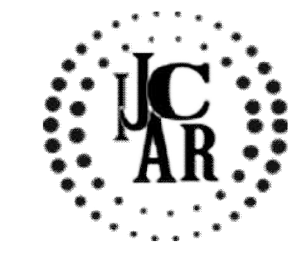

Research Article

\title{
PATIENTS ATTITUDE TOWARDS EXTRACTION OF THIRD MOLAR- A QUESTIONNAIRE BASED STUDY
}

\author{
Harshini Ravichandran and Nabeel Nazar
}

Saveetha Dental College and Hospital, Chennai

\begin{tabular}{|c|c|}
\hline A $R$ R T I C L E $\quad$ I N F O & A B S T R A C T \\
\hline Article History: & \multirow{4}{*}{$\begin{array}{l}\text { The purpose of this study is to assess patients attitude towards extraction of third.The } \\
\text { objective is to assess the attitude of the patient towards extraction of third molar in a } \\
\text { private dental institution. A questionnaire based survey to be conducted among } 50 \text {.The } \\
\text { third molar is the last tooth to erupt in the oral cavity and it is also the most } \\
\text { retained/impacted tooth of the jaws. Even though this tooth can remain asymptomatic } \\
\text { causing no problems whatsoever to the patient, a series of disorders can be directly related } \\
\text { with its presence. It is always debated whether the extraction of the asymptomaticc third } \\
\text { molar is necessary or not. The patients also remain skeptic towards the extraction. The } \\
\text { patients involvement and cooperation in the treatment leads to the success of treatment. } \\
\text { There by it is necessary to assess the patients attitude towards his or her respective } \\
\text { treatment. }\end{array}$} \\
\hline $\begin{array}{l}\text { Received } 19^{\text {th }} \text { January, } 2017 \\
\text { Received in revised form } 5^{\text {th }} \text { February, } 2017 \\
\text { Accepted } 22^{\text {nd }} \text { March, } 2017 \\
\text { Published online } 28^{\text {th }} \text { April, } 2017\end{array}$ & \\
\hline Key words: & \\
\hline Extraction Of Third Molar & \\
\hline
\end{tabular}

Copyright $₫ 2017$ Harshini Ravichandran and Nabeel Nazar. This is an open access article distributed under the Creative Commons Attribution

License, which permits unrestricted use, distribution, and reproduction in any medium, provided the original work is properly cited.

\section{INTRODUCTION}

Third molars exhibit the greatest variability in timing in development, crown and root morphology and position. They are the last teeth to erupt into the oral cavity and supplement the function of the second molars. The eruption or impaction of these teeth is of important consideration in treatment planning and the long-term maintenance of the dentition and therefore of particular interest to the dentist. [1] Third molar surgery is one of the most common surgical procedures performed in general dentistry. Evidence-based healthcare incorporates the 'conscientious, explicit and judicious use of current best evidence in making decisions about the care of individual patientThis approach to healthcare encourages clinicians to interpret evidence on an individual patient basis and to include assessment of patient outcome preference in decision making. Patients' preferences in healthcare settings reflect many factors.[2] It is increasingly apparent that these are both medical and non-medical, and include social, cultural and economic factors.[3] It is possible that these differences affect patient treatment preferences.thereby, patients' satisfaction with dental treatment is important because it will affect their service utilisation pattern. The patient provides critical input into the choice of treatment alternatives based on personal preference for outcomes. With regard to the third molar question. patients may value certain contemporary pain differently than probabilistic future pain.[4]

*Corresponding author: Harshini Ravichandran

Saveetha Dental College and Hospital, Chennai
There by it is necessary to assess the patients attitude towards his or her respective treatment.

\section{MATERIALS AND METHODS}

Questionnaire is distributed to 50 patients visiting a private dental institution, Chennai. Questions were presented based on. The awareness on presence, pain status, extraction procedures and post operative procedures of third molar. It has dealt with various reasons for preferring extraction as well as reason for not getting treated.

\section{RESULTS}

About $95.9 \%$ of the patients were aware of the presence of impacted third molar which reveals a majority group of patients. Among them only $48 \%$ of patients had symptomatic impacted tooth, in which $56.3 \%$ of patients experienced pain or discomfort in relation to 3 rd molar. Only $31.2 \%$ of patients had undergone surgical extraction of the impacted third molar. Almost $83.3 \%$ of patients were aware of the surgical procedure and $80 \%$ of the patients are aware of the post operative sequelae.

When enquired about the pain status, majority of patients reported no pain $(44 \%)$ followed by mild pain pain $(30 \%)$, severe pain $(14 \%)$ and moderate pain $(12 \%)$ respectively. $54 \%$ of patients prefer to extract on the the advise of dentist and majority of patients (74\%) prefer to extract under local anaesthesia when compared under general anaesthesia (26\%). When enquired about the reason for preference of extraction majority of patients (68\%) reported pain followed by mastication (14\%), dentist advise (10\%), other problem $(6 \%)$ 
and $2 \%$ difficulty in speaking. Patients reported that the reason for not getting the treatment done is lack of time $(38.8 \%)$ followed by fear and pain $(26.5 \%)$ and financial $(8.2 \%)$ as the least preffered reason. About $95.9 \%$ of the patients were aware of the presence of impacted third molar which reveals a majority group of patients. Only $31.2 \%$ of patients had undergone surgical extraction of the impacted third molar. Almost $83.3 \%$ of patients were aware of the surgical procedure and $80 \%$ of the patients are aware of the post operative sequelae.
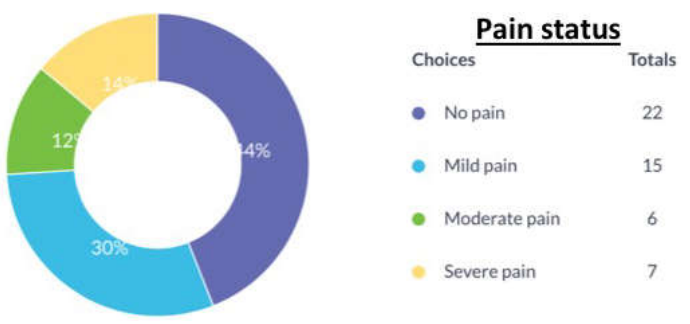

Preference for extraction
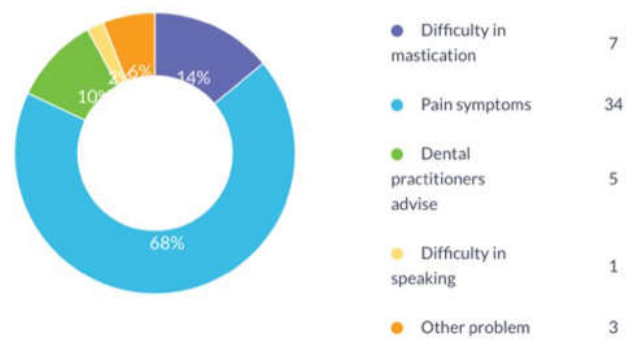

Reason for not getting treated
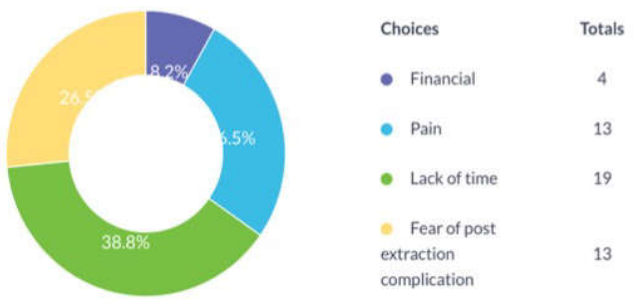

Preference of anaesthetic agent

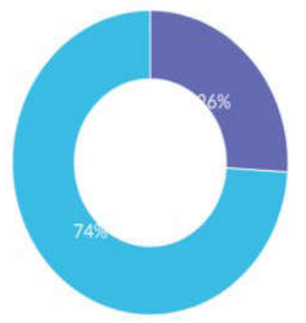

Choices$$
\text { - General }
$$$$
\text { anasthesia }
$$$$
\text { - Local }
$$$$
\text { anasthesia }
$$

\section{DISCUSSION}

Public attitude towards health personnel in general, dentists and dental services in particular are a culmination of life experiences and events. Understanding these attitudes helps dental professionals to appreciate the complexities involved in modifying the attitude and behavior of general public toward oral health care. Public perception of our profession is changing and it is desirable that dentists be aware of that. $[5,6]$ Although most dentists are genuinely interested in rendering quality care, making dental visit a comfortable and nonstressful experience, public views may not always be consistent with dentists' views.[7] Public attitudes towards dentists and dental services determine whether they seek dental care or not and whether they seek preventive or curative dental care. Public attitudes also influence their willingness to accept treatment and the level of anxiety experienced during treatment [8]. Compliance with the health education and self-care practices is also dependent on the public attitude toward dental professional. Ultimately, this information can be used to improve existing services and to plan new ones.[9] Patients' satisfaction is a key to patient compliance and the business success of the dental clinic. Measures of patient satisfaction with dental care may provide useful information to those who want to understand or to predict patient behavior and to those who want to evaluate the dental care providers and services.[10]

Even though respondents have a positive attitude towards regular check-ups, only a very few percentage have actually visited a dentist for extraction in spite of being aware of presence of impacted third molar. This clearly shows a gap between the positive attitude and the actual behavior when it comes to regular dental extraction. About $38.8 \%$ of the subjects agree that dental treatment can be delayed due to lack of time. This highlights that dental visit features lower down in the list of priorities and a sense of ignorance among the respondents. Other reasons for not getting treated was fear of pain and post extraction complication followed by financial reason as the last. Moreover majority of patients neglect extraction of asymptomatic third molar and prefer to wait until any pain symptoms arise, followed by other reasons like difficulty in speaking and mastication. Only $10 \%$ of patients prefer to extract on dentist advise.

This study shows that dentists have a major challenge to face when it comes to educating the public about the importance of prevention of oral diseases. This shows that the public strongly believes in the nobility of dentistry as a profession. Hence, it becomes all the more essential for dentists to live up to the expectations of public.

\section{CONCLUSION}

Removal of the impacted third molar is very important whether symptomatic or asymptomatic. This study reveals patients ignorance and fear as a barrier for treatment. It can be overcome by effective awareness among the patient. It has been proved that effective verbal and nonverbal communication can aid to reduce patient anxiety and thus improve patient satisfaction. Effective patient communication can not only allow the patient to have a thorough understanding of the procedure performed and the expected outcomes but also provide comfort during the treatment. All these will help build a positive rapport with the patient.

\section{Reference}

1. Costa MG, Pazzini CA, Pantuzo MC, Jorge ML, Marques LS. Is there justification for prophylactic extraction of third molars? A systematic review. Braz Oral Res. 2013; 27:183-188.

2. Mercier P, Precious D. Risks and benefits of removal of impacted third molars. A critical review of the literature. Int J Oral Maxillofac Surg. 1992; 21:17-27. [PubMed]

3. Cheung LK, Leung YY, Chow LK, Wong MCM, Chan EKK, Fok YH. Incidence of neurosensory deficits and recovery after lower third molar surgery: a prospective 
clinical study of 4,338 cases. Int J Oral Maxillofac Surg. 2010; 39:320-326. [PubMed]

4. Bouloux GF, Steed MB, Perciaccante VJ. Complications of third molar surgery. Oral Maxillofac Surg Clin North Am. 2007; 19:117-128. [PubMed]

5. Chu CH, Lo EC. Patients' satisfaction with dental services provided by a university in Hong Kong. Int Dent J. 1999; 49:53-59. [PubMed]

6. Glick M. The expectations of patients. J Am Dent Assoc 2010; 141:376-8.
7. Christensen GJ. The credibility of dentists. J Am Dent Assoc 2001; 132:1163-5.

8. Rankin JA, Harris MB. Patients' preferences for dentists' behaviors. J Am Dent Assoc 1985; 110:323-7.

9. DiMatteo MR, McBride CA, Shugars DA, O’Neil EH. Public attitudes toward dentists: A U.S. household survey. J Am Dent Assoc 1995; 126:1563-70.

10. Murtomaa H, Masalin K. Public image of dentists and dental visits in Finland. Community Dent Oral Epidemiol 1982; 10:133-6.

\section{How to cite this article:}

Harshini Ravichandran and Nabeel Nazar (2017) ' Patients Attitude Towards Extraction Of Third Molar- A Questionnaire Based Study', International Journal of Current Advanced Research, 06(04), pp. 3306-3308.

DOI: http://dx.doi.org/10.24327/ijcar.2017.3308.0257 